\title{
Role of iron overload-induced macrophage apoptosis in the pathogenesis of peritoneal endometriosis
}

\author{
Leila Pirdel and Manijeh Pirdel ${ }^{1}$ \\ Department of Immunology, Faculty of Medicine, Islamic Azad University, Ardabil Branch, Ardabil 5615731567, \\ Iran and ${ }^{1}$ Department of Midwifery, Islamic Azad University, Astara Branch, Astara, Iran
}

Correspondence should be addressed to L Pirdel; Email: leilapirdel@yahoo.com

\begin{abstract}
This article presents an overview of the involvement of iron overload-induced nitric oxide (NO) overproduction in apoptosis of peritoneal macrophages of women with endometriosis. We have postulated that the peritoneal iron overload originated from retrograde menstruation or bleeding lesions in the ectopic endometrium, which may contribute to the development of endometriosis by a wide range of mechanisms, including oxidative damage and chronic inflammation. Excessive NO production may also be associated with impaired clearance of endometrial cells by macrophages, which promotes cell growth in the peritoneal cavity. Therefore, further research of the mechanisms and consequences of macrophage apoptosis in endometriosis helps discover novel therapeutic strategies that are designed to prevent progression of endometriosis.

Reproduction (2014) 147 R199-R207
\end{abstract}

\section{Introduction}

Endometriosis is an estrogen-driven inflammatory disease that causes pelvic pain, painful menstrual periods, and infertility (Podgaec et al. 2007, Burney \& Giudice 2012). It is characterized by the growth of endometrial tissue at extrauterine sites, mainly on the ovaries and peritoneum. It affects $\sim 10-15 \%$ of reproductive-aged women. However, the rates have risen by 30 and $50 \%$ in women undergoing laparoscopy to evaluate infertility or chronic pelvic pain respectively (Matarese et al. 2003, Becker \& Amato 2007).

Despite extensive investigations, the physiopathology of endometriosis remains elusive due to its multifactorial characteristics. Accumulated evidence indicates that genetic, hormonal, environmental, immunological, and anatomical factors either alone or in combination may determine the susceptibility to develop endometriosis (Defrere et al. 2006, Hull et al. 2008). The local environment is essentially important in the growth and progression of endometriotic lesions (Kobayashi et al. 2009). Severe hemolysis during retrograde menstruation, along with a defective or overwhelmed peritoneal disposal system in the case of increased menstrual reflux, results in iron overload in the peritoneal environment, which in turn permits attachment and growth of the endometrial cells or fragments (Gazvani \& Templeton 2002). This iron accumulation might have numerous cytotoxic effects as it disrupts the balance between free radicals production and antioxidant defense, which leads to oxidative stress (OS) implicated in the pathogenesis of endometriosis. Several studies state that OS has adverse health effects on the pathogenesis of several diseases, including cancer, atherosclerosis, neurodegenerative disorders, and reproductive system diseases such as pre-eclampsia, and male and female infertility (Jackson et al. 2005, Rahman et al. 2012). Therefore, iron-induced OS may trigger the chain of events resulting in the development and progression of endometriosis (Van Langendonckt et al. 2002a, Carvalho et al. 2012).

In this article, we will summarize the current literatures focused on apoptotic cell death and nitric oxide (NO) with emphasis on the potential role of iron overload in these processes. Based on recent knowledge, we herein suggest that iron overload-induced macrophage apoptosis by overproduction of $\mathrm{NO}$ may play a significant role in the further establishment and growth of endometriotic lesions.

\section{Iron-induced peritoneal OS in endometriosis development}

Iron is an essential nutrient for many metabolic pathways of the body. Iron homeostasis is carefully regulated within the cells by various mechanisms. However, excess iron is considered as a threat to the cells and tissues. Iron toxicity is mainly related to its ability to catalyze the production of a wide variety of damaging 
free radical species in the Fenton reaction, leading to deregulation of cellular processes, cell dysfunction, and eventually to apoptosis or necrosis through lipid peroxidation, protein, and DNA damage (Papanikolaou \& Pantopoulos 2005, Rahman et al. 2012).

The presence of iron overload has been demonstrated in various components of the peritoneal cavity of endometriosis patients (peritoneal fluid, macrophages, and endometriotic lesions; Defrere et al. 2008, Augoulea et al. 2012), which strongly suggests disruption of iron homeostasis in the peritoneal cavity of patients. Iron overload in the peritoneal fluid provokes oxidative injury and inflammatory response, involving peritoneal macrophages in particular, which promote the proliferative capacity of ectopic implants of endometrium in the peritoneal cavity (Van Langendonckt et al. 2002b, Szczepariska et al. 2003).

Generally, oxidative injury occurs when continued delivery of iron to the peritoneal macrophages is associated with inhibition of iron storage in ferritin (Hippeli \& Elstner 1999). This iron accumulation in macrophages may severely compromise their functions. Excessive production of free radicals enhances the activity of nuclear factor kappa B (NFKB), which up-regulates the expression of multiple genes encoding pro-inflammatory cytokines, chemokines, adhesion molecules, growth factor, and angiogenic factor, supporting the inflammatory response, resistance to apoptosis, and cell proliferation in endometriotic lesions (González-Ramos et al. 2007, Lousse et al. 2009). The maintenance of high activity of p65 subunit of NFKB throughout the menstrual cycle owing to progesterone resistance has recently been demonstrated to stimulate an inflammatory response, which promotes the proliferation and survival of ectopic endometrial cell, thereby favoring the establishment and development of peritoneal endometriosis (González-Ramos et al. 2012). Macrophages also serve as the source of other inflammatory mediators contributing to the development of endometriosis, including NO. NO produced in abundance by the inducible form of $\mathrm{NO}$ synthase (iNOS, NOS2), induced by oxidant-sensitive transcription factors like $N F \kappa B$, has the potential to exacerbate endometriosis by promoting inflammation and necrosis at the site of lesion (Beckman \& Koppenol 1996, Detmers et al. 2000). Moreover, the peritoneal accumulation of pro-oxidant and pro-inflammatory factors during retrograde menstruation, such as hemoglobin and its by-product heme, may cause OS-mediated mesothelial layer damage and chronic inflammation, permitting the attachment and development of endometrial fragments in the peritoneum. Decreased expression of inducible HMOX1 (HO-1) by peritoneal macrophages and mesothelial cells impairs hemoglobin and heme detoxification in the case of endometriosis (Van Langendonckt et al. 2002c).
Altered immune responses play a prominent role in the development of peritoneal endometriosis due to failure to remove the ectopic endometrial cells (Giudice \& Kao 2004, Mier-Cabrera et al. 2010). Numerous evidences indicate that the immune cells facilitate the establishment of endometriotic lesion and modulate endometriosis-associated pain and infertility as well (Berbic et al. 2009).

Macrophages are the predominant type of cell in the peritoneal fluid of patients with endometriosis. These cells are recruited in response to chronic stimuli such as ectopic endometrial implants as a foreign entity and/or excessive refluxed menstrual debris secreting high levels of chemotactic agents, including monocyte chemotactic protein 1 (MCP1), RANTES, and lyso-phosphatidylcholine (lyso-pc) (Oral et al. 1996, Santanman et al. 2002). Recruited macrophages are also highly active and release various mediators such as pro-inflammatory cytokines (IL1, IL6, and TNF $\alpha$ ), prostaglandins, growth factors, and angiogenic factors and express inducible enzymes (iNOS and COX2) (Gazvani \& Templeton 2002, Berkkanoglu \& Arici 2003, Dmowski \& Braun 2004, Dionyssopoulou et al. 2005). All these products mediate inflammation and neovascularization, thereby promoting the growth of implanted endometrial fragments (Lebovic et al. 2001, Gazvani \& Templeton 2002, Matarese et al. 2003, Berbic et al. 2009). The differential expression of proteins involved in iron metabolism can affect the functional polarization of macrophages into classically activated M1 and alternatively activated M2 phenotypes (Cairo et al. 2011, Recalcati et al. 2012). The iron retention-prone M1 macrophages are characterized by up-regulated iron storage ferritin $(\mathrm{FtH})$ that is accompanied by the down-regulation of transferrin receptor 1 (TfR1) and iron exporter ferroportin (Fpn) due to decreased activity of the iron regulatory protein 2 (IREB2 (IRP2)), a primary regulator of iron homeostasis within the cell, which in turn limits the labile iron pool (LIP) to protect themselves from oxidative damage (Corna et al. 2010, Recalcati et al. 2010). These cells perform several effector functions, including bacteriostatic activity, secretion of pro-inflammatory cytokines, immunostimulation, and tumor suppression, by inducing a polarized Th1 response (Gaetano et al. 2010, Recalcati et al. 2012). Hepcidin-mediated Fpn down-regulation has been reported to result in iron accumulation in M1 macrophages, which may contribute to wound healing or chronic inflammation (Recalcati et al. 2012). By contrast, immunosuppressive M2 macrophages resolve inflammation and promote parasite killing, angiogenesis, wound healing, matrix remodeling, and tumor growth by increasing the availability of extracellular iron and polarized Th2 responses (Brunelli \& Rovere-Querini 2008, Corna et al. 2010, Gaetano et al. 2010, Recalcati et al. 2010). The phenotypic characteristics of these cells are $\mathrm{FtH}^{\text {low }} / \mathrm{Fpn}^{\text {high }} / \mathrm{TfR} 1^{\text {high }} /$ hemoglobin-haptoglobin scavenger receptor $\mathrm{CD} 163^{\text {high }} /$ hemopexin-bound heme 
receptor $\mathrm{CD} 19^{\text {high }} / \mathrm{HMOX} 1^{\text {high }}$ with high capacity for iron release which may affect other cells in the microenvironment (Gaetano et al. 2010, Recalcati et al. 2012). Capobianco et al. (2011) demonstrated a supportive role of $\mathrm{CD}_{163}{ }^{+}$pro-angiogenic Tek (Tie2)-expressing macrophages in angiogenesis and accelerated growth of ectopic lesions.

The inflammatory peritoneal environment characterizes macrophage polarization toward the M2 phenotype expressing markers of alternative activation, particularly high levels of scavenger receptors, CD163 and CD206, which are involved in the export of hemederived iron and removal of inflammatory mediators respectively (Smith et al. 2012, Capobianco \& RovereQuerini 2013). Impaired ability of peritoneal macrophages to dispose apoptotic endometrial remnants and defective scavenging heme-bound iron, resulting from cyclic progesterone withdrawal, may activate macrophages recruited at sites of local hypoxia and tissue stress (Capobianco \& Rovere-Querini 2013). The activation of peritoneal macrophages by the environmental cues such as local hypoxia and iron overload may provide a permissive environment to vascularization and growth of ectopic endometriosis lesions via reduced immune clearance of endometrial cells (Bacci et al. 2009). It should be noted that plasticity of macrophage polarization may occur in endometriosis. Tissue damaging as a consequence of sustained M1 polarization may be associated with an increase in the response of the M2 cells, which supports the persistent growth of ectopic endometrial tissue (Smith et al. 2012).

\section{Pleiotropic activities of NO in the endometrium}

An increase in the number and activity of macrophages is also accompanied by release of NO (Gupta et al. 2006). NO is a highly reactive multifunctional molecule with dichotomous regulatory roles in both physiological and pathological processes (Chen et al. 2001), which is synthesized enzymatically from L-arginine by three isoforms of NOSs, including neuronal NOS (NOS1 (nNOS)), inducible NOS (NOS2), and endothelial NOS (NOS3 (eNOS)) (Karpuzoglu \& Ahmed 2006, Mori 2007). NO is well known to act as a neurotransmitter and vasorelaxant agent, and is involved in antimicrobial defense mechanisms (Guix et al. 2005). With respect to apoptosis, NO exerts both pro- and anti-apoptotic actions. The complexity is attributed to its interactions with other molecules such as iron, reactive oxygen species (ROS), metal ions, and proteins (Chung et al. 2001, Kim et al. 2001). Induction of NOS2, particularly in mononuclear phagocytes (monocytes and macrophages), produces excessive $\mathrm{NO}$ in response to numerous stimuli such as tissue injury, inflammation, cytokines, and growth factors (Rosselli 1997). This may be accompanied by increased ROS production, exacerbating tissue injury. $\mathrm{NO}$ reaction with superoxide anion generates a strong oxidant peroxynitrite $\left(\mathrm{OONO}^{-}\right)$ which can react with biological molecules in a number of mechanisms, particularly oxidizing iron/sulfur centers, zinc finger, and protein thiols (Beckman \& Koppenol 1996, Detmers et al. 2000, Liu et al. 2005). In the reproductive system, NO plays an important physiological role in female reproductive processes, including ovulation, sperm motility and fertilization, implantation, pregnancy, and labor (Ledingham et al. 2000, Wu et al. 2003). Excessive generation of NO by activated macrophages negatively affects fertility by changing the composition of the peritoneal environment and impairing ovulation, fertilization, and early embryonic development (Agarwal et al. 2005, Gupta et al. 2006).

$\mathrm{NO}$, along with prostaglandin $\mathrm{E}_{2}$ and prostacyclin $\mathrm{I}_{2}$, participates in the initiation and control of menstrual bleeding (Telfer et al. 1997). Luteal phase progesterone up-regulates NOS3-derived NO production from both glandular epithelium and endometrial vessels, leading to vasodilation and endometrial receptivity. After onset of bleeding as a consequence of progesterone withdrawal, an increased NOS2-generated NO, which is induced by pro-inflammatory cytokines produced by endometrium, including IL1 and TNF $\alpha$, may on one hand maintain vasodilation and on the other hand inhibit platelet aggregation (Cameron \& Campbell 1998, Tschugguel et al. 1998, Chwalisz \& Garfield 2000). Furthermore, $\mathrm{NO}$ contributes to metalloproteinase-mediated cyclic destruction of endometrium and induction of apoptosis in endometrial cells by reversing the balance between anti-apoptotic BCL2 and pro-apoptotic BAX proteins observed during menstruation or embryo implantation (Cameron \& Campbell 1998, Chwalisz \& Garfield 2000, Castro et al. 2002). Sex steroids are also involved in the regulation of apoptosis in human endometrium. Blocking the FAS/FASLG(FASL)-mediated apoptosis in the proliferative endometria via estrogen-mediated $\mathrm{BCL} 2$ expression is associated with the retention of co-expressed FAS and FASLG within the cells that is followed by BAX expression and the FAS/FASLGmediated apoptosis of endometrial cells in response to progesterone withdrawal, either in an autocrine or paracrine manner by soluble FASLG (Song et al. 2002). Li et al. (2001) established that NO synergistic with progesterone may enhance apoptotic susceptibility of endometrial epithelial cells by increasing the activation of the p38 MAPK pathway, which facilitates trophoblast implantation and invasion. Progesterone may affect the up-regulation of NOS3 and NOS2 expression in endometrial epithelial cells and also stimulation of NOS3 phosphorylation through both the PI3/Akt and the ERK $1 / 2$ pathways (Khoram \& Han 2009). The differential regulatory function of $\mathrm{NO}$ has also been confirmed by L-arginine treatment followed by a significant increase in apoptosis of proliferative not secretory endometrial implants. This indicates more sensitivity of the cells for activation of apoptotic 
machinery that has not already been induced by high generation of local endogenous factors, such as cytokine and NO (Castro et al. 2002, Johnson et al. 2004). Therefore, the endometrial microenvironment during the proliferative phase has been suggested to affect the response of the secretory endometria in the menstruation process (Johnson et al. 2004).

The peritoneal fluid in women with endometriosis and/or unexplained infertility has been shown to contain high levels of NO (Lee et al. 2004). Induction of NOS2 and hence $\mathrm{NO}$ synthesis by macrophages have increased in response to IFN $\gamma$ and $\mathrm{TNF} \alpha$ with lipopolysaccharide (LPS) in the endometriotic peritoneal fluid (Alpay et al. 2006). The endometrium of women with endometriosis and adenomyosis exhibited persistent overexpression of NOS3 throughout the menstrual cycle, which was associated with chronic inflammation damaging early embryonic development (Ota et al. 1998, Cao et al. 2004). The up-regulation of glandular NOS3 in association with reduced expression of $\alpha_{v} \beta_{3}$ integrin in response to high levels of local inflammatory cytokines and estrogen may enforce a positive feedback loop in the further growth of implanted lesions by activating cyclooxygenase-2 and aromatase (Khorram \& Lessey 2002). Chen et al. (2001) demonstrated that embryo apoptosis induced by excessive amounts of $\mathrm{NO}$ is followed by embryo fragmentation and subsequently early embryo loss, implying that this may be a contributing factor in endometriosis-associated infertility through the up-regulation of TP53 (p53) and BAX expression in a cGMP-independent pathway. A number of studies have found higher activity of NOS2 and more $\mathrm{NO}$ production by peritoneal macrophages from infertile women with endometriosis after immunological stimulation, which is an important determinant of the inflammation in the peritoneum (Dong et al. 2001, Osborn et al. 2002, Wu et al. 2003). GnRH analogs have been proven as effective factors in the treatment of endometriosis and adenomyosis by regulating the secretion of estradiol, resulting in marked reduction in $\mathrm{NO}$ production and peroxynitrite formation (Kamada et al. 2000). Recently, Greene et al. (2013) showed the regulatory role of Larginine in NO-mediated enhancement of endometrial growth through increased BAD phosphorylation, which is accompanied by reduced apoptosis. Nevertheless, further studies are necessary to elucidate the significance of $\mathrm{NO}$ in the pathogenesis of endometriosis.

\section{Molecular mechanisms of apoptotic cell death induced by NO}

Recent studies have indicated that $\mathrm{NO}$ modulates apoptosis, or programmed cell death, in several cell types, including inflammatory cells (Shaw et al. 2005). Apoptosis, characterized by a series of morphological and biochemical alterations, eliminates excess or unwanted cells from tissue without inducing an inflammatory reaction to maintain tissue homeostasis (Vignali et al. 2002). However, apoptotic deregulation is implicated in the pathogenesis of several human diseases (Nakagawa et al. 2000). A variety of extrinsic and intrinsic signals trigger apoptosis. NO has recently been recognized as an inducer of apoptosis (Brüne et al. 1998a); however, the effect of NO on cell apoptosis is controversial. On one side, NO provokes apoptosis, while on the other side, it protects cells from apoptotic cell death. This can be partly attributed to the rate of $\mathrm{NO}$ production, but to a large extent may be dependent on intracellular redox state and redox capacity within cells (Weigert \& Brune 2008). NO-induced DNA damage has been demonstrated to result in p53 accumulation that activates caspase family proteases involved in both the mitochondrial and Fas/FasL signaling pathways (Bahat et al. 2004). The endoplasmic reticulum (ER) stressCHOP pathway may also account for p53-independent cell death when $\mathrm{p} 53$ response is not predominant (Brüne 2003). The mitochondria-dependent apoptosis pathway is initiated by the down-regulation of anti-apoptotic proteins, e.g., BCL2 and BCL2L1 (BCLXL), concurrent with the up-regulation of pro-apoptotic proteins, e.g., BAX, BAK1 (BAK), and BID (Li \& Wogan 2005). Proapoptotic proteins act either by opening mitochondrial permeability transition pores directly resulting in release of some pro-apoptotic factors such as cytochrome $C$, AIF, endonuclease G, and smac/DIABLO (second mitochondrial derived activator of caspase/direct IAP-binding protein with low pl) or by binding to antiapoptotic proteins to prevent their actions (Guha et al. 2006; Fig. 1). NO can result in inhibition of mitochondrial respiration, thereby leading to depletion of

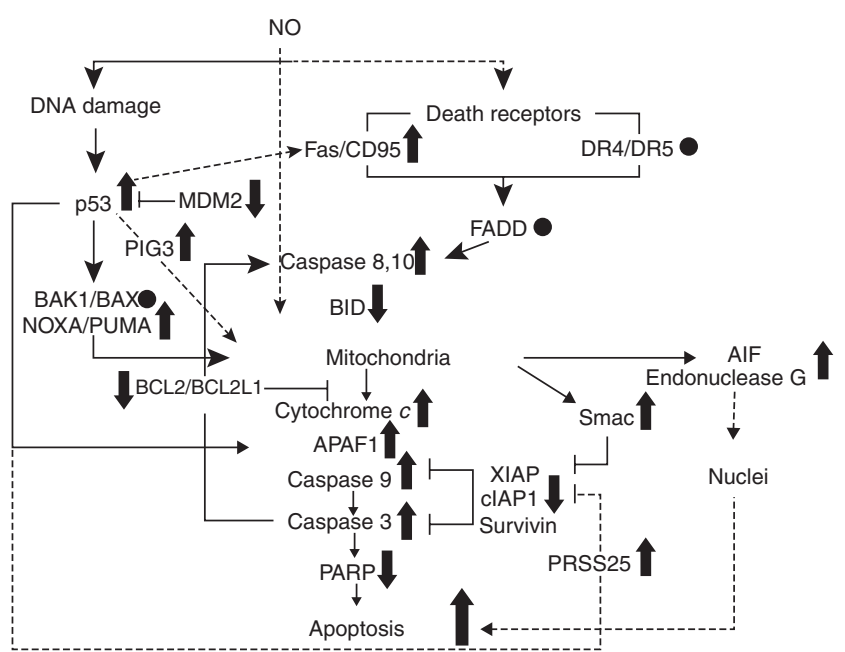

Figure 1 Schematic summary of alterations in apoptotic signaling pathways under NO treatment. DR4 and DR5, death receptor 4 and 5 respectively; AIF, apoptosis-inducing factor; APAF1, apoptotic protease-activating factor; XIAP, X chromosome-linked inhibitor of apoptosis; cIAP1, cellular inhibitor of apoptosis protein 1. Data adapted from Li et al. (2005). 
ATP that stimulates superoxide anion $\left(\mathrm{O}_{2}^{-}\right)$production by competing with molecular oxygen for binding sites on cytochrome $c$ oxidase in mitochondria and then its reaction with $\mathrm{NO}$ to form peroxynitrite $\left(\mathrm{ONOO}^{-}\right)$ (Oyama et al. 2002). Superoxide formation may also occur by other enzymatic routes, for example, xanthine oxidase induced by $\mathrm{TNF} \alpha$ and IFN $\gamma$ ( $\mathrm{Hu}$ \& Brindle 2005). Overexpressed xanthine oxidase localized to glandular epithelium has been observed in adenomyosis and endometriosis during early secretory phase of menstrual cycle (Ota et al. 2001). Excessive generation of $\mathrm{NO}$ or peroxynitrite induces apoptosis through multiple mechanisms, including irreversible inhibition of complex I by s-nitrosation that is followed by inhibition of mitochondrial aconitase and complex III through removal of iron from Fe-S centers, which in turn results in mitochondrial dysfunction, cytochrome $C$ release, and consequently caspase-dependent apoptosis (Li \& Wogan 2005). It has previously been reported that $\mathrm{NO}$ and peroxynitrite can react with $\mathrm{Fe}-\mathrm{S}$ clusters of cytosolic aconitase, which induces the transition from aconitase to iron regulatory protein 1 (ACO1 (IRP1)) as a consequence of total cluster disruption and causes an increase in the LIP by repressing ferritin translation and reduction in ferritin pool (Bouton et al. 1997, Murgia et al. 2002, Galleano et al. 2004). Ferritin synthesis is considered as a part of cytoprotective responses to control oxidative damage in the setting of iron overload. Thus, ablation of the induction of ferritin synthesis markedly accelerates oxidative damage (Balla et al. 1992). Moreover, NO activates poly (ADP-ribose) polymerase (PARP) resulting in depletion of NAD+ and ATP, which is associated with chromatin condensation and DNA fragmentation (Chen et al. 2001).

The apparent role of apoptosis in the physiopathology of endometriosis has gained a lot of interest. Accumulated evidence indicates that decreased apoptosis of endometrial cells in a phase-dependent manner during the menstrual cycle may facilitate ectopic survival of implanted endometrial fragments (Dmowski et al. 2001, Garcia-Velasco \& Arici 2003). In healthy women, the endometrium that is refluxed into the peritoneum undergoes apoptosis called anoikis because of its failure to interact with the extracellular matrix required for the growth of ectopic endometrium (Béliard et al. 2004). The resistance of endometrial cells to apoptosis and their increased sensitivity to proliferation is one of the proposed theories for the development of endometriosis (Harada et al. 2004). Intrinsic resistance of refluxed endometrial cells to apoptosis may promote their adherence to the peritoneal mesothelial cells, thereby provoking cell proliferation and neoangiogenesis to develop active endometriosis (Park et al. 2009). Meresman et al. (2000) confirmed the pathological role of apoptosis in endometriosis by detecting up-regulated expression of the anti-apoptotic factor BCL2 that is accompanied by reduced expression of the pro-apoptotic factor BAX. Moreover, the location of endometriosis determines the expression level of proapoptotic proteins involved in the different apoptotic pathways (Dufournet et al. 2006).

In eutopic endometrium from women with endometriosis, it has been indicated that up-regulation of $M Y C(c-M y c)$ by estradiol in the absence of TGF $\beta 1$ is associated with decreased BAX expression reducing apoptosis in the late secretory phase in these patients compared with normal endometrium, favoring survival and implantation of ectopic endometrial cells (Johnson et al. 2005).

The iron burden that is imposed on peritoneal macrophages by unrestrained phagocytosis of refluxed erythrocytes, together with overwhelmed HMOX1dependent heme degradation, may be lethal to the cells and subsequently result in release of pro-oxidants such as iron and heme into the peritoneum (Defrere et al. 2008, Lousse et al. 2012). Macrophages have specific sensitivity to NO-mediated apoptotic cell death in a cGMP-independent manner, which may be associated with inhibition of protective proteins such as heme oxygenase, metallothionin, and heat shock proteins (Brüne et al. 1998b, Kim et al. 1999, Choi et al. 2002). Long-term activation can induce apoptosis in peritoneal macrophages. However, an increase in the proportion of highly active BCL2-positive peritoneal macrophages during both phases of the menstrual cycle in women with endometriosis may have important effects on the growth and vascularization of ectopic endometrium (McLaren et al. 1997). Bcl2 overexpression has already been demonstrated to inhibit NO-induced apoptosis through PARP cleavage (Messmer \& Brüne 1995).

The Fas/FasL death pathway is one of the major apoptotic pathways. Apoptosis of eutopic and ectopic endometrial tissues may be less relied on FAS expression (Agic et al. 2009). A study by Garcia-Velasco et al. (2002) showed that elevated apoptosis of FAS-expressing immune cells in the peritoneal cavity of women with advanced endometriosis is attributed to high levels of soluble FASLG, impairing the removal of ectopic endometrial cells. This suggests a role for apoptotic deregulation in the pathophysiology of endometriosis.

Elevated macrophage-derived growth factors in the peritoneal fluid up-regulate the expression of FASLG involved in apoptosis of activated T cells and macrophages within the ectopic endometrial implants. This leads to the development of immune tolerance and longterm survival of endometrial cells by increasing resistance to macrophage-mediated cytolysis during the initial attachment in the peritoneal cavity (Ota et al. 1998, Garcia-Velasco et al. 1999, Garcia-Velasco \& Arici 2003, Agic et al. 2009). Accordingly, iron overload in peritoneal macrophages of women with endometriosis may play a pathological role in the development and progression of the disease. 


\section{Conclusion}

Although mitochondria (intrinsic pathway) and/or Fas death receptor (extrinsic pathway) contribute to macrophage apoptosis, the cell death cascades need to be fully clarified during NO-mediated apoptosis. Based on the reviewed studies, iron overload-induced OS may permit ectopic survival of endometrial cells and lesion vascularization in the peritoneal cavity. It is tempting to propose that excessive $\mathrm{NO}$ in the peritoneal fluid of women with endometriosis may play a role in the iron overload-induced mitochondrial/and or death receptor apoptosis pathways to cause progression of endometriosis. NO and ROS have recently been demonstrated to disturb ER functions as ER stressors, which in turn trigger apoptosis (Gotoh \& Masataka 2006). NO overproduction has the potential of ER stress-induced apoptosis implicated in the pathogenesis of various human diseases, including atherosclerosis, diabetes, heart failure, and neurodegenerative disorders (Okada et al. 2004, Liu et al. 2005, Xu et al. 2005, Malhotra \& Kaufman 2007, Tabas 2010). Therefore, further studies must aim to elucidate the exact and detailed role of apoptosis pathways through the mitochondrial and/or ER stress pathways in the disease, and determine whether modulators of $\mathrm{NO}$ synthesis and ER stress with iron chelators can provide a useful basis for new therapeutic approaches.

\section{Declaration of interest}

The authors declare that there is no conflict of interest that could be perceived as prejudicing the impartiality of the review.

\section{Funding}

Research support was provided by the Medical Faculty, Ardabil Branch, Islamic Azad University.

\section{Acknowledgements}

The authors wish to sincerely thank Dr Mahmood Mazhar for reviewing the manuscript.

\section{References}

Agarwal A, Gupta S \& Sharma RK 2005 Role of oxidative stress in female reproduction. Reproductive Biology and Endocrinology 3 1-21. (doi:10.1186/1477-7827-3-28)

Agic A, Djalali S, Diedrich K \& Hornung D 2009 Apoptosis in endometriosis. Gynecologic and Obstetric Investigation 68 217-223. (doi:10.1159/000235871)

Alpay Z, Saed GM \& Diamond MP 2006 Female infertility and free radicals: potential role in adhesions and endometriosis. Journal of the Society for Gynecologic Investigation 13 390-398. (doi:10.1016/j.jsgi.2006. 05.002)
Augoulea A, Alexandrou A, Creatsa M, Vrachnis N \& Lambrinoudaki I 2012 Pathogenesis of endometriosis: the role of genetics, inflammation and oxidative stress. Archives of Gynecology and Obstetrics 286 99-103. (doi:10.1007/s00404-012-2357-8)

Bacci M, Capobianco A, Monno A, Cottone L, Puppo FD, Camisa B, Mariani M, Brignole C, Ponzoni M, Ferrari S et al. 2009 Macrophages are alternatively activated in patients with endometriosis and required for growth and vascularization of lesions in a mouse model of disease. American Journal of Pathology 175 547-556. (doi:10.2353/ajpath.2009.081011)

Bahat RS, Bhaskaran M, Mongia A, Hitosugi N \& Singhal PC 2004 Morphine-induced macrophage apoptosis: oxidative stress and strategies for modulation. Journal of Leukocyte Biology 75 1-8. (doi:10.1189/jlb. 1203639)

Balla G, Jacob HS, Balla J, Rosenberg M, Nath K, Apple F, Eaton JW \& Vercellotti GM 1992 Ferritin: a cytoprotective antioxidant stratagem of endothelium. Journal of Biological Chemistry $26718148-18153$.

Becker CM \& Amato RJD 2007 Angiogenesis and antiangiogenic therapy in endometriosis. Microvascular Research 74 121-130. (doi:10.1016/j.mvr. 2007.04.008)

Beckman JS \& Koppenol WH 1996 Nitric oxide, superoxide, and peroxynitrite: the good, the bad, and the ugly. American Journal of Physiology 271 1424-1437.

Béliard A, Noël A \& Foidart JM 2004 Reduction of apoptosis and proliferation in endometriosis. Fertility and Sterility 82 80-85. (doi:10. 1016/j.fertnstert.2003.11.048)

Berbic M, Schulke L, Markham R, Tokushige N, Russell P \& Fraser IS 2009 Macrophage expression in endometrium of women with and without endometriosis. Human Reproduction 24 325-332. (doi:10.1093/humrep/den393)

Berkkanoglu M \& Arici A 2003 Immunology and endometriosis. American Journal of Reproductive Immunology 50 48-59. (doi:10.1034/j.16000897.2003.00042.x)

Bouton C, Hirling H \& Drapier JC 1997 Redox modulation of iron regulatory proteins by peroxynitrite. Journal of Biological Chemistry 272 19969-19975. (doi:10.1074/jbc.272.32.19969)

Brüne B 2003 Nitric oxide: NO apoptosis or turning it ON? Cell Death and Differentiation 10 864-869. (doi:10.1038/sj.cdd.4401261)

Brüne B, Knethen AV \& Sandau KB 1998a Nitric oxide and its role in apoptosis. European Journal of Pharmacology 351 261-272. (doi:10. 1016/S0014-2999(98)00274-X)

Brüne B, Sandau K \& von Knethen A 1998 b Apoptotic cell death and nitric oxide: activating and antagonistic transducing pathways. Biochemistry $63817-825$.

Brunelli S \& Rovere-Querini P 2008 The immune system and the repair of skeletal muscle. Pharmacological Research 58 117-121. (doi:10.1016/ j.phrs.2008.06.008)

Burney RO \& Giudice LC 2012 Pathogenesis and pathophysiology of endometriosis. Fertility and Sterility 98 511-519. (doi:10.1016/ j.fertnstert.2012.06.029)

Cairo G, Recalcati S, Mantovani A \& Locati M 2011 Iron trafficking and metabolism in macrophages: contribution to the polarized phenotype. Trends in Immunology 32 241-247. (doi:10.1016/j.it.2011.03.007)

Cameron IT \& Campbell S 1998 Nitric oxide in the endometrium. Human Reproduction Update 4 565-569. (doi:10.1093/humupd/4.5.565)

Cao X, Yang D, Song M, Murphy A \& Parthasarathy S 2004 The presence of endometrial cells in the peritoneal cavity enhances monocyte recruitment and induces inflammatory cytokines in mice: implications for endometriosis. Fertility and Sterility 82 999-1007. (doi:10.1016/ j.fertnstert.2004.04.040)

Capobianco A \& Rovere-Querini P 2013 Endometriosis, a disease of the macrophage. Frontiers in Immunology 4 1-14. (doi:10.3389/fimmu. 2013.00009)

Capobianco A, Monno A, Cottone L, Venneri MA, Biziato D, Di Puppo F, Ferrari S, De Palma M, Manfredi AA \& Rovere-Querini P 2011 Proangiogenic $\mathrm{Tie}^{+}$macrophages infiltrate human and murine endometriotic lesions and dictate their growth in a mouse model of the disease. American Journal of Pathology 179 2651-2659. (doi:10.1016/j. ajpath.2011.07.029)

Carvalho LF, Samadder AN, Agarwal A, Fernandes LF \& Abrão MS 2012 Oxidative stress biomarkers in patients with endometriosis: systematic review. Archives of Gynecology and Obstetrics 286 1033-1040. (doi:10.1007/s00404-012-2439-7) 
Castro A, Johnson MC, Anido M, Cortinez A, Gabler F \& Vega M 2002 Role of nitric oxide and bcl-2 family genes in the regulation of human endometrial apoptosis. Fertility and Sterility 78 587-595. (doi:10.1016/ S0015-0282(02)03304-6)

Chen HW, Jiang WS \& Tzeng CR 2001 Nitric oxide as a regulator in preimplantation embryo development and apoptosis. Fertility and Sterility 75 1163-1171. (doi:10.1016/S0015-0282(01)01780-0)

Choi BM, Pae HO, Jang SI, Kim YM \& Chung HT 2002 Nitric oxide as a proapoptotic as well as anti-apoptotic modulator. Journal of Biochemistry and Molecular Biology 35 116-126. (doi:10.5483/BMBRep.2002.35. 1.116)

Chung HT, Pae HO, Choi BM, Billiar TR \& Kim YM 2001 Nitric oxide as a bioregulator of apoptosis. Biochemical and Biophysical Research Communications 282 1075-1079. (doi:10.1006/bbrc.2001.4670)

Chwalisz K \& Garfield RE 2000 Role of nitric oxide in implantation and menstruation. Human Reproduction 15 96-111. (doi:10.1093/humrep/ 15.suppl_3.96)

Corna G, Campana L, Pignatti E, Castiglioni A, Tagliafico E, Bosurgi L, Campanella A, Brunelli S, Manfredi AA, Apostoli P et al. 2010 Polarization dictates iron handling by inflammatory and alternatively activated macrophages. Haematologica 95 1814-1822. (doi:10.3324/ haematol.2010.023879)

Defrere S, Van Langendonck AV, Vaesen S, Jouret M, González-Ramos R, Gonzalez D \& Donnez J 2006 Iron overload enhances epithelial cell proliferation in endometriotic lesions induced in a murine model. Human Reproduction 21 2810-2816. (doi:10.1093/humrep/del261)

Defrere S, Lousse JC, Ramos G, Colette S, Donnez I \& Van Langendonckt V 2008 Potential involvement of iron in the pathogenesis of peritoneal endometriosis. Molecular Human Reproduction 14 377-385. (doi:10. 1093/molehr/gan033)

Detmers PA, Hernandez M, Mudgett J, Hassing H, Burton C, Mundt S, Chun S, Fletcher D, Card DJ, Lisnock JM et al. 2000 Deficiency in inducible nitric oxide synthase results in reduced atherosclerosis in apolipoprotein E-deficient mice. Journal of Immunology $\mathbf{1 6 5}$ 3430-3435.

Dionyssopoulou E, Vassiliadis S, Evangeliou A, Koumantakis EE \& Athanassakis I 2005 Constitutive or induced elevated levels of Lcarnitine correlate with the cytokine and cellular profile of endometriosis. Journal of Reproductive Immunology 65 159-170. (doi:10.1016/ j.jri.2004.12.002

Dmowski WP \& Braun DP 2004 Immunology of endometriosis. Best Practice \& Research. Clinical Obstetrics \& Gynaecology 18 245-263. (doi:10.1016/j.bpobgyn.2004.02.001)

Dmowski WP, Ding J, Shen J, Rana N, Fernandez BB \& Braun DP 2001 Apoptosis in endometrial glandular and stromal cells in women with and without endometriosis. Human Reproduction 16 1802-1808. (doi:10.1093/humrep/16.9.1802)

Dong M, Shi Y, Cheng Q \& Hao M 2001 Increased nitric oxide in peritoneal fluid from women with idiopathic infertility and endometriosis. Journal of Reproductive Medicine 46 887-891.

Dufournet C, Uzan C, Fauvet R, Cortez A, Siffroi JP \& Dara E 2006 Expression of apoptosis-related proteins in peritoneal, ovarian and colorectal endometriosis. Journal of Reproductive Immunology $\mathbf{7 0}$ 151-162. (doi:10.1016/j.jri.2005.11.003)

Gaetano C, Massimo L \& Alberto M 2010 Control of iron homeostasis as a key component of macrophage polarization. Haematologica 95 1801-1803. (doi:10.3324/haematol.2010.030239)

Galleano M, Simontacchi M \& Puntarulo S 2004 Nitric oxide and iron: effect of iron overload on nitric oxide production in endotoxemia. Molecular Aspects of Medicine 25 141-154. (doi:10.1016/j.mam.2004. 02.015)

Garcia-Velasco JA \& Arici A 2003 Apoptosis and the pathogenesis of endometriosis. Seminars in Reproductive Medicine 21 165-171. (doi:10.1055/s-2003-41323)

Garcia-Velasco JA, Arici A, Zreick T, Naftolin F \& Mor G 1999 Macrophage-derived growth factors regulate FasL expression in endometrial stromal cells: a role in endometriosis. Molecular Human Reproduction 5 642-650. (doi:10.1093/molehr/5.7.642)

Garcia-Velasco JA, Mulayim N, Kayisli UA \& Arici A 2002 Elevated soluble Fas ligand levels may suggest a role for apoptois in women with endometriosis. Fertility and Sterility 78 855-859. (doi:10.1016/S00150282(02)03320-4)
Gazvani R \& Templeton A 2002 Peritoneal environment, cytokines and angiogenesis in the pathophysiology of endometriosis. Reproduction $\mathbf{1 2 3}$ 217-226. (doi:10.1530/rep.0.1230217)

Giudice LC \& Kao L 2004 Endometriosis. Lancet 364 1789-1799. (doi:10.1016/S0140-6736(04)17403-5)

González-Ramos R, Donnez J, Defrere S, Leclercq I, Squifflet J \& Lousse JC 2007 Nuclear factor- $\kappa$ B is constitutively activated in peritoneal endometriosis. Molecular Human Reproduction 13 503-509. (doi:10.1093/ molehr/gam033)

González-Ramos R, Rocco J, Rojas C, Sovino H, Poch A, Kohen P, Alvarado-Díaz C \& Devoto L 2012 Physiologic activation of nuclear factor $\kappa-B$ in the endometrium during the menstrual cycle is altered in endometriosis patients. Fertility and Sterility 97 645-651. (doi:10.1016/j. fertnstert.2011.12.006)

Gotoh T \& Masataka M 2006 Nitric oxide and endoplasmic reticulum stress. Arteriosclerosis, Thrombosis, and Vascular Biology 26 1439-1446. (doi:10.1161/01.ATV.0000223900.67024.15)

Greene JM, Feugang JM, Pfeiffer KE, Stokes JV, Bowers SD \& Ryan PL 2013 L-Arginine enhances cell proliferation and reduces apoptosis in human endometrial RL95-2 cells. Reproductive Biology and Endocrinology 11 15. (doi:10.1186/1477-7827-11-15)

Guha M, Kumar S, Choubey V, Maity P \& Bandyopadhyay U 2006 Apoptosis in liver during malaria: role of oxidative stress and implication of mitochondrial pathway. FASEB Journal 20 1-11. (doi:10.1096/fj. 05-5338fje)

Guix FX, Uribesalgo T \& Muñoz FJ 2005 The physiology and pathophysiology of nitric oxide in the brain. Progress in Neurobiology 76 126-152. (doi:10.1016/j.pneurobio.2005.06.001)

Gupta S, Agarwal A, Krajcir N \& Alvarez J 2006 Role of oxidative stress in endometriosis. Reproductive Biomedicine Online 13 126-134. (doi:10.1016/S1472-6483(10)62026-3)

Harada T, Kaponis A, Iwabe T, Taniguchi F, Makrydimas G, Sofikitis N, Paschopoulos M, Paraskevaidis E \& Terakawa N 2004 Apoptosis in human endometrium and endometriosis. Human Reproduction Update 10 29-38. (doi:10.1093/humupd/dmh007)

Hippeli S \& Elstner EF 1999 Transition metal ion-catalyzed oxygen activation during pathogenic processes. FEBS Letters 443 1-7. (doi:10. 1016/S0014-5793(98)01665-2)

Hu DE \& Brindle KM 2005 Immune cell-induced synthesis of NO and reactive oxygen species in lymphoma cells causes their death by apoptosis. FEBS Letters 579 2833-2841. (doi:10.1016/j.febslet.2005. 03.099)

Hull ML, Escareno CR, Godsland JM, Doig JR, Johnson CM, Phillips SC, Smith SK, Tavaré S, Print CG \& Charnock-Jones DS 2008 Endometrialperitoneal interactions during endometriotic lesion establishment. American Journal of Pathology 173 700-715. (doi:10.2353/ajpath. 2008.071128)

Jackson LW, Schisterman EF, Rao RD, Browne R \& Armstrong D 2005 Oxidative stress and endometriosis. Human Reproduction 20 2014-2020. (doi:10.1093/humrep/dei001)

Johnson MC, Maliqueo M, Boric MA, Villavicencio A, Vantman D \& Vega M 2004 Differential in vitro actions of nitric oxide on human endometrial cell survival. Fertility and Sterility $\mathbf{8 1}$ 176-184. (doi:10.1016/j.fertnstert.2003.05.018)

Johnson MC, Torres M, Alves A, Bacallao K, Fuentes A, Vega M \& Boric MA 2005 Augmented cell survival in eutopic endometrium from women with endometriosis: expression of c-myc. TGF- $\beta 1$ and bax genes. Reproductive Biology and Endocrinology 3 45. (doi:10.1186/14777827-3-45)

Kamada Y, Nakatsuka M, Asagiri K, Noguchi S, Habara T, Takata M \& Kudo T $2000 \mathrm{GnRH}$ agonist-suppressed expression of nitric oxide synthases and generation of peroxynitrite in adenomyosis. Human Reproduction 15 2512-2519. (doi:10.1093/humrep/15.12.2512)

Karpuzoglu E \& Ahmed SA 2006 Estrogen regulation of nitric oxide and inducible nitric oxide synthase (iNOS) in immune cells: implications for immunity, autoimmune diseases, and apoptosis. Nitric Oxide $\mathbf{1 5}$ 177-186. (doi:10.1016/j.niox.2006.03.009)

Khoram O \& Han G 2009 Influence of progesterone on endometrial nitric oxide synthase expression. Fertility and Sterility 91 2157-2162. (doi:10.1016/j.fertnstert.2008.05.019) 
Khorram O \& Lessey BA 2002 Alterations in expression of endometrial endothelial nitric oxide synthase and $\alpha_{v} \beta_{3}$ integrin in women with endometriosis. Fertility and Sterility 78 860-864. (doi:10.1016/S00150282(02)03347-2)

Kim YM, Bombeck CA \& Billiar TR 1999 Nitric oxide as a bifunctional regulator of apoptosis. Circulation Research 84 253-256. (doi:10.1161/ 01.RES.84.3.253)

Kim PKM, Zamora R, Petrosko P \& Billiar T 2001 The regulatory role of nitric oxide in apoptosis. International Immunopharmacology $\mathbf{1}$ 1421-1441. (doi:10.1016/S1567-5769(01)00088-1)

Kobayashi H, Yamada Y, Kanayama S, Furukawa N, Noguchi T, Haruta S, Yoshida S, Sakata M, Sado T \& Oi H 2009 The role of iron in the pathogenesis of endometriosis. Gynecological Endocrinology 25 39-52. (doi:10.1080/09513590802366204)

Lebovic DI, Mueller MD \& Taylor RN 2001 Immunobiology of endometriosis. Fertility and Sterility 75 1-10. (doi:10.1016/S00150282(00)01630-7)

Ledingham MA, Thomson A, Young A, Macara LM, Greer IA \& Norman JE 2000 Changes in the expression of nitric oxide synthase in the human uterine cervix during pregnancy and parturition. Molecular Human Reproduction 6 1041-1048. (doi:10.1093/molehr/6.11.1041)

Lee TH, Wu MY, Chen MJ, Chao KH, Ho HN \& Yang YS 2004 Nitric oxide is associated with poor embryo quality and pregnancy outcome in in vitro fertilization cycles. Fertility and Sterility 82 126-131. (doi:10.1016/ j.fertnstert.2004.02.097)

Li CQ \& Wogan GN 2005 Nitric oxide as a modulator of apoptosis. Cancer Letters 226 1-15. (doi:10.1016/j.canlet.2004.10.021)

Li HY, Chang SP, Yuan CC, Chao HT, Ng HT \& Sung YJ 2001 Nitric oxide induces extensive apoptosis endometrial epithelial cells in the presence of progesterone: involvement of mitogen-activated protein kinase pathways. Molecular Human Reproduction 7 755-763. (doi:10.1093/ molehr/7.8.755)

Liu YH, Carretero OA, Cingolani OH, Liao TD, Sun Y, Xu J, Li LY, Pagano PJ, Yang JJ \& Yang XP 2005 Role of inducible nitric oxide synthase in cardiac function and remodeling in mice with heart failure due to myocardial infarction. American Journal of Physiology. Heart and Circulatory Physiology 289 2616-2623. (doi:10.1152/ajpheart.00546.2005)

Lousse JC, Defrere S, Langendonckt AV, Gras J, Ramos RG, Colette S \& Donnez J 2009 Iron storage is significantly increased in peritoneal macrophages of endometriosis patients and correlates with iron overload in peritoneal fluid. Fertility and Sterility 91 1668-1675. (doi:10.1016/j. fertnstert.2008.02.103)

Lousse JC, Van Langendonckt A, Defrere S, Ramos RG, Colette S \& Donnez J 2012 Peritoneal endometriosis is an inflammatory disease. Frontiers in Bioscience 4 23-40. (doi:10.2741/E358)

Malhotra JD \& Kaufman RJ 2007 Endoplasmic reticulum stress and oxidative stress: a vicious cycle or a double-edged sword? Antioxidants \& Redox Signaling 9 2277-2293. (doi:10.1089/ars.2007.1782)

Matarese G, Placido GD, Nikas Y \& Alviggi C 2003 Pathogenesis of endometriosis: natural immunity dysfunction or autoimmune disease? Trends in Molecular Medicine 9 225-228. (doi:10.1016/S14714914(03)00051-0)

McLaren J, Prentice A, Charnock-Jones DS, Sharkey AM \& Smith SK 1997 Immunolocalization of the apoptosis regulating protein $\mathrm{BCl}-2$ and $\mathrm{Bax}$ in human endometrium and isolated peritoneal fluid macrophages in endometriosis. Human Reproduction 12 146-152. (doi:10.1093/humrep/12.1.146)

Meresman GF, Vighi S, Buquet RA, Contreras-Ortiz O, Tesone M \& Rumi LS 2000 Apoptosis and expression of $\mathrm{BCl}-2$ and Bax in eutopic endometrium from women with endometriosis. Fertility and Sterility 74 760-766. (doi:10.1016/S0015-0282(00)01522-3)

Messmer UK \& Brüne B 1995 Nitric oxide-induced apoptosis: p53dependent and p53-independent signalling pathways. Biochemical Journal 319 299-305.

Mier-Cabrera J, Jiménez-Zamudio L, García-Latorre E, Cruz-Orozco O \& Hernández-Guerrero C 2010 Quantitative and qualitative peritoneal immune profiles, T-cell apoptosis and oxidative stress-associated characteristics in women with minimal and mild endometriosis. BJOG : an International Journal of Obstetrics and Gynaecology 118 6-16. (doi:10.1111/j.1471-0528.2010.02777.x)

Mori M 2007 Regulation of nitric oxide synthesis and apoptosis by arginase and arginine recycling. Journal of Nutrition 137 1616-1620.
Murgia I, Delledonne M \& Soave C 2002 Nitric oxide mediates ironinduced ferritin accumulation in Arabidopsis. Plant Journal 30 521-528. (doi:10.1046/j.1365-313X.2002.01312.x)

Nakagawa T, Zhu H, Morishima N, Li E, Xu J, Yankner BA \& Yuan J 2000 Caspase-12 mediates endoplasmic-reticulum-specific apoptosis and cytotoxicity by amyloid- $\beta$. Nature 403 98-103. (doi:10.1038/47513)

Okada K, Minamino T, Tsukamoto Y, Liao Y, Tsukamoto O, Takashima S, Hirata A, Fujita M, Nagamachi Y, Nakatani T et al. 2004 Prolonged endoplasmic reticulum stress in hypertrophic and failing heart after construction: possible contribution of endoplasmic reticulum stress to cardiac myocyte apoptosis. Circulation 110 705-712. (doi:10.1161/01. CIR.0000137836.95625.D4)

Oral E, Olive DL \& Arici A 1996 The peritoneal environment in endometriosis. Human Reproduction Update 2 385-398. (doi:10.1093/ humupd/2.5.385)

Osborn BH, Haney AF, Misukonis MA \& Weinberg JB 2002 Inducible nitric oxide synthase expression by peritoneal macrophages in endometriosisassociated infertility. Fertility and Sterility 77 46-51. (doi:10.1016/ S0015-0282(01)02940-5)

Ota H, Igarashi S, Hatazawa J \& Tanaka T 1998 Endothelial nitric oxide synthase in the endometrium during the menstrual cycle in patients with endometriosis and adenomyosis. Fertility and Sterility 69 303-308. (doi:10.1016/S0015-0282(97)00478-0)

Ota H, Igarashi S \& Tanaka T 2001 Xanthine oxidase in eutopic and ectopic endometrium in endometriosis and adenomyosis. Fertility and Sterility 75 785-790. (doi:10.1016/S0015-0282(01)01670-3)

Oyama JI, Frantz S, Blais C, Kelly RA \& Bourcier T 2002 Nitric oxide, cell death, and heart failure. Heart Failure Reviews 7 327-334. (doi:10.1023/ A:1020758300499)

Papanikolaou G \& Pantopoulos K 2005 Iron metabolism and toxicity. Toxicology and Applied Pharmacology 202 199-211. (doi:10.1016/ j.taap.2004.06.021)

Park JS, Lee JH, Kim M, Chang HJ, Hwang KJ \& Chang KH 2009 Endometrium from women with endometriosis shows increased proliferation activity. Fertility and Sterility 92 1246-1249. (doi:10. 1016/j.fertnstert.2009.04.025)

Podgaec S, Abrao MS, Dias JA Jr, Rizzo LV, de Oliveira RM \& Baracat EC 2007 Endometriosis: an inflammatory disease with a Th2 immune response component. Human Reproduction 22 1373-1379. (doi:10. 1093/humrep/del516)

Rahman T, Hosen I, Islam MM \& Shekhar HU 2012 Oxidative stress and human health. Advances in Bioscience and Biotechnology 3 997-1019. (doi:10.4236/abb.2012.327123)

Recalcati S, Locati M, Marini A, Santambrogio P, Zaninotto F, De Pizzol M, Zammataro L, Girelli D \& Cairo G 2010 Differential regulation of iron homeostasis during human macrophage polarized activation. European Journal of Immunology 40 824-835. (doi:10.1002/eji. 200939889)

Recalcati S, Locati M, Gammella E, Invernizzi P \& Cairo G 2012 Iron levels in polarized macrophages: regulation of immunity and autoimmunity. Autoimmunity Reviews 11 883-889. (doi:10.1016/j.autrev. 2012.03.003)

Rosselli M 1997 Nitric oxide and reproduction. Molecular Human Reproduction 3 639-641. (doi:10.1093/molehr/3.8.639)

Santanman N, Murphy AA \& Parthasarathy S 2002 Macrophages, oxidation, endometriosis. Annals of the New York Academy of Sciences 955 183-198. (doi:10.1111/j.1749-6632.2002.tb02779.x)

Shaw CA, Taylor EL, Megson IL \& Rossi AG 2005 Nitric oxide and the resolution of inflammation: implications for atherosclerosis. Memórias do Instituto Oswaldo Cruz 100 67-71. (doi:10.1590/S007402762005000900012)

Smith KA, Pearson CB, Hachey AM, Xia DL \& Wachtman LM 2012 Alternative activation of macrophages in rhesus macaques (Macaca mulatta) with endometriosis. Comparative Medicine 62 303-310.

Song J, Rutherford T, Naftolin F, Brown S \& Mor G 2002 Hormonal regulation of apoptosis and the Fas and Fas ligand system in human endometrial cells. Molecular Human Reproduction 8 447-455. (doi:10.1093/molehr/8.5.447)

Szczepariska M, Kozlik J, Skrzypczak J \& Mikolajczyk M 2003 Oxidative stress may be a piece in the endometriosis puzzle. Fertility and Sterility 79 1288-1293. (doi:10.1016/S0015-0282(03)00266-8) 
Tabas I 2010 The role of endoplasmic reticulum stress in the progression of atherosclerosis. Circulation Research 107 15-18. (doi:10.1161/CIRCRESAHA.110.224766)

Telfer JF, Irvine GA, Kohnen G, Campbell S \& Cameron IT 1997 Expression of endothelial and inducible nitric oxide synthase in non-pregnant and decidualized human endometrium. Molecular Human Reproduction 3 69-75. (doi:10.1093/molehr/3.1.69)

Tschugguel W, Schneeberger C, Unfried G, Czerwenka K, Weninger W, Mildner M, Bishop JR \& Huber JC 1998 Induction of inducible nitric oxide synthase expression in human secretory endometrium. Human Reproduction 13 436-444. (doi:10.1093/humrep/13.2.436)

Van Langendonckt AV, Casanas F \& Donnez J 2002a Oxidative stress and peritoneal endometriosis. Fertility and Sterility 77 861-870. (doi:10. 1016/S0015-0282(02)02959-X)

Van Langendonckt AV, Roux FC \& Donnez J 2002b Iron overload in the peritoneal cavity of women with pelvic endometriosis. Fertility and Sterility 78 712-718. (doi:10.1016/S0015-0282(02)03346-0)

Van Langendonckt AV, Casanas F, Dolmans MM \& Donnez J 2002C Potential involvement of hemoglobin and heme in the pathogenesis of peritoneal endometriosis. Fertility and Sterility 77 561-569. (doi:10.1016/S0015-0282(01)03211-3)
Vignali $M$, Mirco Infantino $M$, Matrone $R$, Chiodo I, Somigliana E, Busacca M \& Vigano P 2002 Endometriosis: novel etiopathogenetic concepts and clinical perspectives. Fertility and Sterility 78 665-678. (doi:10.1016/S0015-0282(02)03233-8)

Weigert A \& Brune B 2008 Nitric oxide, apoptosis and macrophage polarization during tumor progression. Nitric Oxide 19 95-102. (doi:10.1016/j.niox.2008.04.021)

Wu MY, Chao KH, Yang JH, Lee TH, Yang YS \& Ho HN 2003 Nitric oxide synthesis is increased in the endometrial tissue of women with endometriosis. Human Reproduction 18 2668-2671. (doi:10.1093/ humrep/deg484)

Xu C, Balliy-Maitre B \& Reed JC 2005 Endoplasmic reticulum stress: cell life and dead decisions. Journal of Clinical Investigation 115 2656-2664. (doi:10.1172/JCl26373)

Received 31 October 2013

First decision 19 December 2013

Revised manuscript received 27 February 2014

Accepted 5 March 2014 